\title{
IdeAs
}

Idées d'Amériques

3 | 2012

L'alimentation dans les Amériques au prisme des sciences sociales

\section{La fragmentation des frontières nationales et l'assemblage des paysages alimentaires : des aliments mexicains aux États Unies à la nourriture internationale au Mexique}

A fragmentação das fronteiras nacionais e a remontagem das paisagens alimentares : de alimentos mexicanos nos EUA à comida internacional no México The Fragmentation of National Boundaries and the Combination of Dietary Landscapes: From Mexican Food in the Unites-States to International Food in Mexico

\section{OpenEdition}

Journals

Édition électronique

URL : https://journals.openedition.org/ideas/511

DOI : 10.4000/ideas.511

ISSN : 1950-5701

Éditeur

Institut des Amériques

Référence électronique

Dr. Maximino MATUS RUIZ, « La fragmentation des frontières nationales et l'assemblage des paysages alimentaires : des aliments mexicains aux États Unies à la nourriture internationale au Mexique », IdeAs [En ligne], 3 | 2012, mis en ligne le 05 mars 2019, consulté le 20 octobre 2022. URL http://journals.openedition.org/ideas/511 ; DOI : https://doi.org/10.4000/ideas.511

Ce document a été généré automatiquement le 20 octobre 2022

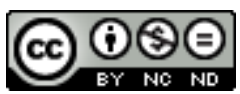

Creative Commons - Attribution - Pas d'Utilisation Commerciale - Pas de Modification 4.0 International - CC BY-NC-ND 4.0

https://creativecommons.org/licenses/by-nc-nd/4.0/ 


\title{
La fragmentation des frontières nationales et l'assemblage des paysages alimentaires : des aliments mexicains aux États Unies à la nourriture internationale au Mexique
}

\author{
A fragmentação das fronteiras nacionais e a remontagem das paisagens \\ alimentares : de alimentos mexicanos nos EUA à comida internacional no México \\ The Fragmentation of National Boundaries and the Combination of Dietary \\ Landscapes: From Mexican Food in the Unites-States to International Food in \\ Mexico
}

Dr. Maximino MATUS RUIZ

\section{Introducción}

En las urbes estadounidenses es común que en los barrios conformados por comunidades de migrantes latinoamericanos se comercialice una diversidad de productos relacionados con sus países de origen. La venta de alimentos crudos y preparados de forma itinerante en las calles, desde las casas, y en restaurantes establecidos formalmente son prácticas recurrentes. Los principales consumidores de estos alimentos son los propios migrantes. Empero, en muchas ocasiones estos actores también incorporan dentro de sus dietas algunos alimentos distintivos de la sociedad receptora, así como de la diversidad de los grupos étnicos con los que conviven. Por ejemplo, algunos restaurantes mayas/yucatecos de San Francisco ofertan en su menú alimentos italianos y asiáticos. En la ciudad de México encontramos un fenómeno 
similar para el caso de los establecimientos y restaurantes que comercializan alimentos colombianos. Estos espacios además de ser frecuentados por migrantes del país sudamericano, son visitados por diversos comensales latinoamericanos, quienes en el extranjero se han identificado con este paisaje alimentario y además, han promovido su traducción al demandar a los empresarios que también comercialicen parte de sus gastronomías nacionales.

2 Las hibridaciones de las practicas alimentarias de los migrantes en los espacios de destino también afecta a los miembros de sus comunidades originarias : los alimentos y sus símbolos relacionados, no solo son trasladados por las poblaciones migrantes del sur al norte del continente americano, sino que también lo hacen en forma contraria. De hecho, en ocasiones siguen un camino errante antes de llegar a su destino. Tal es el caso de la comunidad maya de Oxcutzcab, en el suroeste de México, donde es común encontrar restaurantes que ofertan comida asiática, italiana, francesa, salvadoreña y "estadounidense". En tiempos recientes, algunos alimentos distintivos de estas gastronomías internacionales han pasado a formar parte de los rituales comunitarios. Por lo tanto, es posible argumentar que el mantenimiento o cambio de las prácticas alimentarias de los migrantes tiene repercusiones transnacionales; no sólo promueven la fragmentación de fronteras territoriales para trasladar clandestinamente alimentos, sino que además, suscitan el reensamblaje de panoramas alimentarios relacionados con territorios foráneos y la traducción de aquellos con los que se relacionan en el nuevo ambiente al que son introducidos.

3 En este artículo dichos temas serán explorados a partir de la descripción de algunas prácticas realizadas por miembros de comunidades migrantes para trasladar y traducir paisajes alimentarios entre EUA y Latinoamérica. En primera instancia se presentan los conceptos centrales que son utilizados a lo largo de la exposición para analizar la información etnográfica ${ }^{1}$. En seguida se expone el traslado de alimentos latinoamericanos desde EUA y Colombia, que se comercializan en la ciudad de México. Después se explican las particularidades del traslado de los alimentos oaxaqueños/ zapotecos que son distribuidos en comercios de Los Ángeles (California). Por último se analiza el traslado de alimentos yucatecos/mayas a San Francisco (California), y las gastronomías internacionales comercializadas en la comunidad de Oxcutzcab (Yucatán). En las conclusiones se identifican las tendencias principales de los casos presentados y se discute la pertinencia de crear leyes de excepción para los alimentos venidos allende las fronteras que son comercializados predominantemente entre comunidades migrantes.

\section{Traslado, traducción e impugnación de los paisajes alimentarios}

4 Trazando las redes semánticas entre el término alemán landschaft y el ingles landscape, Cosgrove afirma que la "idea del paisaje" es "...una forma moderna característica de encontrar y representar el mundo externo : en sus cualidades pictóricas y graficas, en su espacialidad y formas de conectar lo individual con la comunidad" (Cosgrove, 2006 : 5-6). Diversos investigadores han analizado las implicaciones ideológicas de estas representaciones paisajisticas (Daniels, 1993 ; Mitchell, 1996 ; Mitchell, 2002 ; Olwig 2005 ; Cosgrove, 2006). Particularmente han enfatizado su relación con la lógica de 
reproducción del capitalismo y la hegemonía del Estado-Nación; la coherencia en la representación enmascara la explotación y exclusión de un sin numero de actores.

Los estudios del paisaje inspiraron a otros investigadores a utilizar el término para analizar sus conexiones con la comida a través del concepto "paisaje alimentario" (foodscape). Dicho término fue originalmente propuesto por Yasmeen (1997) en su tesis doctoral sobre género, comida y espacio público en Bangkok : "Paisaje alimentario, proviene de paisaje, es un término usado para describir un proceso de ver un lugar en el que la comida es utilizada como un lente para traer a foco relaciones humanas seleccionadas" (Yasmeen, $2008: 523$. Traducción propia). Por su parte, en otra tesis doctoral sobre "paisajes alimentarios festivos" en Gilroy, Texas, Adema (2006) retomó el concepto de la siguiente forma : “...cuando la asociación entre un lugar y una comida es abstraída y promovida, y la comida se convierte en emblemática de un lugar, el paisaje comunal se convierte en paisaje alimentario. Cuando una localidad pone en escenografía un performance de su identidad a través de la comida, se convierte en paisaje alimentario festivo" (Adema, 2006 : VI. Traducción propia).

Desde las perspectivas antes descritas, los paisajes alimentarios emergen cuando la comida se convierte en la entidad primordial para definir el paisaje de un lugar, región o nación; la comida provee un campo semántico donde los elementos constitutivos de un paisaje se organizan en relación a ciertos alimentos. Estos se expresan en diferentes modalidades : festivales, restaurantes, envoltorios de comida, etc. Al igual que las representaciones paisajísticas, cuando entran al mercado en forma de productos, los paisajes alimentarios guardan una relación indirecta con la ontología física de un lugar (Johnston et al., 2009 : 512-513).

8 Tim Ingold ha sido crítico con los estudios del paisaje que solo hacen énfasis en la dimensión expresiva del fenómeno, es decir, en las representaciones. En su lugar, ha propuesto una aproximación fenomenológica donde tanto los organismos como las cosas están conectados por la extensión de sus "líneas fluidas de vida". Ingold argumenta que en los tiempos modernos, estas líneas han sido fragmentadas en puntos, en su mayoría al servicio del capital y el Estado-Nación. Como resultado, hoy en día viajamos del punto A al punto B sin saber que hay en medio; ocupamos el espacio en lugar de habitarlo (Ingold, 2006, 2007). Siguiendo esta línea argumentativa y retomando la teoría de los mundos de vida - umwelt - de Jakob von Uexkül (1992 [1934]), propongo que un acercamiento fenomenológico a los paisajes alimentarios implicaría concebirlos como la forma específica en que los organismos se relacionan con el medio ambiente y perciben a otros organismos y cosas, con la finalidad de proveerse de comida y evitar ser comidos. En el caso específico de los humanos, un paisaje alimentario organizado por las líneas fluidas de vida, sería el de un campesino que produce maíz para el autoconsumo. Mientras que, un paisaje alimentario donde las líneas fluidas de vida han sido fragmentadas en puntos, puestos al servicio del capital y del Estado-Nación, sería el de los alimentos "étnicos" y "exóticos" venidos de los "países del sur", que se comercializan en los "países del norte" con leyendas y representaciones paisajísticas que denotan un origen idealizado. Así, los consumidores del norte consumen alimentos provenientes de un punto A, que son comercializados en un punto B, sin saber lo que hay en medio.

9 Como alternativa a las perspectivas que sólo privilegian el análisis de la representación o la experimentación del paisaje, coincido con los investigadores canadienses cuando 
argumentan que si bien, los paisajes alimentarios envuelven elementos de materialidad e ideología, en la práctica estos espacios también son impugnados por actores que luchan por definir su terreno de acción política para acceder a los alimentos (Johnston et al., 2009 : 512-513). Por ejemplo, las prácticas emprendidas por los migrantes para trasladar e introducir clandestinamente alimentos entre diferentes países, ponen en cuestión el rol de las empresas transnacionales y el Estado-Nación en la comercialización y establecimiento de normas que regulan la comercialización de comida venida allende las fronteras. En este sentido, es posible argumentar que las normas de calidad -oficiales y populares- de diferentes paisajes alimentarios -origen y destino- entran en conflicto. Por lo tanto, estas poblaciones se ven en la necesidad de buscar alternativas para introducir clandestinamente sus alimentos a los países donde residen o transitan temporalmente (Matus, 2011). A diferencia de los consumidores de productos "étnicos" y "exóticos" que no saben que hay entre el punto A y B, la mayoría de los migrantes conocen las líneas fluidas de vida que unen estos puntos y a los actores que las recorren para lograr reensamblar paisajes alimentarios fuera de sus territorios originarios.

10 En este artículo, en lugar de cambiar el foco de atención de las representaciones paisajísticas (Daniels, 1993 ; Mitchell, 1996 ; Mitchell, 2002 ; Olwig 2005 ; Cosgrove 2006) a las líneas de vida de los organismos y las cosas que habitan en los paisajes (Ingold, 2006, 2007), se analiza cómo los paisajes alimentarios son constituidos y objetados continuamente por una diversidad de actores. Particularmente se explora la forma en que el traslado clandestino de alimentos entre EUA y diversos países latinoamericanos promueve el reensamblaje de paisajes alimentarios en territorios diferentes con los que comúnmente están relacionados. Se argumenta que el ensamblaje de la representación y experimentación paisajística, ha promovido la emergencia de una economía que basa su reproducción en la contaminación de la pasión (Latour y Lépinay, 2009) por alimentos provenientes allende las fronteras.

\section{Alimentos sudamericanos en la ciudad de México}

11 En la década de 1990 un mexicano conocido como "El paisa" comenzó a ofrecer alimentos colombianos en un mercado de la ciudad de México. Casualmente, dicho mercado se encuentra ubicado sobre la calle de Medellín, en la colonia Roma. Por lo tanto, en lugar de nombrarlo por su nombre original (Melchor Ocampo), este lugar es conocido popularmente como "El mercado de Medellín".

Los locatarios que hasta el año 2012 vendían este tipo de productos, recordaron que su comercialización inicial fue impulsada por la llegada a México de un contenedor cargado de alimentos frescos -papa criolla, brevas, chontaduros y enlatadosprovenientes de Colombia. El paisa adquirió estos productos y los distribuyó entre otros locatarios del mercado. Pocos meses después llegó un contenedor con sodas y jugos colombianos y en seguida otro de pan y galletas. La demanda inicial por dichos alimentos fue escasa, sin embargo, ésta aumentó conforme el numero de refugiados y migrantes colombianos en la ciudad de México se incrementó en la década de 1990, consecuencia de la guerrilla y el narcotráfico en el país sudamericano.

Algunos comerciantes entrevistados aseguraron que en realidad, el motivo que impulsó la comercialización de alimentos colombianos en el mercado de Medellín, fue la impresión que dos mujeres colombianas causaron en El paisa, quien para no 
decepcionar a sus virtuales clientas, se comprometió a conseguir los productos demandados. Su pasional búsqueda lo llevó al encuentro de un contenedor de productos colombianos que adquirió de forma impulsiva, y para minimizar las perdidas económicas, los comenzó a ofertar entre diversos locatarios. Mito popular o verdad olvidada, lo cierto es que gracias a la audacia de El paisa, el mercado de Medellín pronto se convirtió en centro estratégico para el acaparamiento y la comercialización de alimentos colombianos en México.

La diversidad de alimentos colombianos ofertados en el mercado de Medellín se fue ampliando conforme los consumidores fueron demandando productos particulares a los locatarios y éstos fueron descubriendo formas alternativas para hacerse de los mismos. Los pedidos especiales de alimentos no tardaban más de un mes en ser entregados. Cuando se trataba de verduras y frutas colombianas que según cuentan los locatarios, eran prohibidas en México, éstos debían actuar con mucha cautela antes de aceptar surtir el producto, ya que temían que las autoridades sanitarias los multaran. Para adquirir este tipo de alimentos los consumidores tenían que solicitarlos varias veces y generar confianza con los comerciantes. Una vez que estos últimos se cercioraban de las buenas intenciones de los primeros, el producto era entregado.

Con el paso de los años, se convirtió en práctica común, que antes o después de viajar hacia o desde Colombia, los migrantes visitaran a los dueños de estos locales para preguntarles si necesitaban algún alimento en especial $u$ ofrecerles productos colombianos. Ésta era una práctica realizada comúnmente con la finalidad de disminuir el costo del pasaje aéreo mediante la reventa de alimentos. De igual manera, algunas personas comenzaron a ofrecer a los locatarios comida colombiana preparada en casa : patacones, pan, arepas, tamales, etc.

Los locatarios del mercado de Medellín también comenzaron a realizar viajes a Colombia para adquirir directamente los alimentos y transportarlos por avión a México. Asimismo, con el tiempo estas personas incursionaron en la comercialización de alimentos mexicanos en Colombia. Empero, debido a que estos actores no se encontraban debidamente acreditados ante las autoridades aduanales para trasladar alimentos entre México y Colombia, fueron desarrollando diversas habilidades para quebrantar la seguridad fronteriza de los aeropuertos. Una práctica común era dividir pequeñas cantidades de producto entre diferentes acompañantes y viajar en horarios con poca vigilancia aeroportuaria.

17 Uno de los locatarios comentó que a inicios del siglo XXI migrantes venezolanos comenzaron a visitar el mercado en busca de alimentos de su país. Era común que estas personas se sorprendieran al percatarse de productos venezolanos que eran comercializados bajo marcas colombianas. El dueño del local les explicaba que el producto era básicamente el mismo, no obstante, la empresa productora había migrado a Colombia para protegerse de una posible expropiación por parte del gobierno de Hugo Chávez. Además, el locatario también explicó que en ocasiones, antes de viajar a Venezuela, algunos migrantes visitaban su negocio para comprar alimentos "venezolanos" que ya no se comercializaban en su país y de esta manera compartirlos con sus familiares y amigos a su regreso.

18 En años recientes, este local también comenzó a ofertar alimentos brasileños. La emergencia de este nuevo mercado fue impulsada por la llegada de la iglesia evangélica Pare de sufrir a México - filial de la brasileña Iglesia Universal del Reino de Dios (IURD) - y la apertura de una de sus mayores sedes a pocas cuadras del mercado de Medellín. Los 
fines de semana, después de asistir al culto, algunos brasileños empezaron a visitar el mercado para comprar productos colombianos y venezolanos, y además comenzaron a demandar alimentos de su país. Para hacerse de estos productos, el locatario concretó alianzas con algunos distribuidores que importaban productos latinoamericanos desde los EUA. Además, solicitó a su clientela brasileña que lo contactaran con alguien que supiera cocinar comidas de su país. De esta manera ubicó a una persona que desde entonces le surte chorizo de res y pao de queijo (pan de queso) preparado en casa.

19 A inicios del siglo XXI se constituyeron algunas sociedades empresariales de migrantes para trasladar alimentos colombianos entre Estados Unidos y México. Estos productos no sólo eran comercializados entre los locatarios del mercado, sino que también comenzaron a ser distribuidos entre los diferentes restaurantes colombianos que comenzaban a establecerse en la ciudad de México. Uno de estos colectivos fue conformado por Carlos, un estudiante colombiano que migró a la ciudad de México con la finalidad de realizar estudios de maestría en economía. No obstante, pronto inició labores en una empresa de consultoría. Tras relacionarse con otros colombianos en México, Carlos conoció a Alejandra en una fiesta de paisanos. Alejandra le comentó que anteriormente trasladaba alimentos colombianos por avión y los vendía en el mercado de Medellín y algunos restaurantes, pero tiempo después dejó de hacerlo porque las ganancias eran mínimas. Para ese entonces Carlos ya tenía conocimiento sobre la existencia de una tienda de productos Colombianos en McAllen (Texas) y propuso a Alejandra conformar una sociedad para trasladar alimentos por esa ruta. Debido a que Carlos no contaba con visa estadounidense, decidió convocar a Felipe, un amigo colombiano que sí la tenía, a unirse a la sociedad. De esta forma, Alejandra aportaría su conocimiento sobre la operación del negocio y sus diversos contactos entre la comunidad colombiana radicada en la ciudad de México, Felipe su visa estadounidense y Carlos su auto para realizar los viajes y su conocimiento en economía.

20 La sociedad conformada por Carlos, Alejandra y Felipe operó durante el año 2007. Debido a que los miembros de este colectivo empresarial trabajaban entre semana, los viajes a la frontera norte de México eran realizados en días no laborales. La travesía empezaba el viernes a las 9pm. Carlos manejaba desde la ciudad de México con destino a Reynosa, a donde llegaban a las 10am del siguiente día. Mientras Carlos descansaba en un hotel, Alejandra y Felipe cruzaban la frontera para adquirir los alimentos colombianos en una tienda de McAllen. Preferían los alimentos empaquetados sobre los que se vendían a granel, ya que los primeros eran más fáciles de transportar. La excepción era la harina pan, utilizada para preparar las arepas. Una vez adquiridos los productos, Alejandra y Felipe regresaban a Reynosa. Si acaso los detenían en la aduana, argumentaban que los alimentos eran para una fiesta familiar. Una vez en Reynosa, empaquetaban los productos perecederos en hieleras y regresaban a la ciudad de México pasada la media noche del sábado. De esta forma evitaban la revisión del punto fitosanitario que se encontraba a $90 \mathrm{~km}$ de Reynosa. Tan pronto llegaban a la ciudad de México, los productos eran distribuidos entre algunos restaurantes y locatarios del mercado de Medellín. Por lo común adquirían $\$ 1500$ dólares de alimentos que revendían al doble. Tras descontar lo invertido en el viaje, su ganancia final era de aproximadamente $\$ 600$ dólares. Sus mejores clientes eran los restaurantes, ya que pagaban en efectivo y siempre demandaban este tipo de productos.

21 Después de algunos meses de trabajar en el traslado de alimentos, Carlos invitó a Alejandra a colaborar en algunos proyectos de la consultoría donde laboraba. Este 
hecho implicó la disolución del colectivo empresarial que habían constituido, ya que en un viaje que Alejandra realizó a Reynosa como representante de la consultoría, aprovechó para comprar productos colombianos en McAllen y transpórtalos por avión a la ciudad de México. Cuando Carlos se enteró de esta actividad, rompió toda relación con Alejandra ya que lo consideró un abuso de confianza. Tiempo después, Carlos comenzó a realizar viajes a Colombia junto con Felipe con la finalidad de adquirir alimentos y comercializarlos en México. Sin embargo, esta sociedad también se disolvió, ya que en uno de los viajes tuvieron diferencias respecto a las ganancias generadas.

Después de las experiencias antes descritas, Carlos quedo decepcionado y decidió dejar de comercializar alimentos colombianos. Sin embargo, él esta seguro de que pudo haber conformado un negocio exitoso, siempre y cuando hubiera trabajado con la gente correcta. Durante nuestra entrevista recordó que en el año 2007 la demanda por la comida colombiana en México era muy alta y aun habían muchos productos que tenían potencial de mercado. Pero, en el año 2012 la demanda por estos alimentos había disminuido considerablemente. Al cuestionarle sobre las razones que impulsaron la contracción de este mercado, Carlos consideró que pudo ser consecuencia de la guerra contra el narcotráfico emprendida por el gobierno de Felipe Calderón en México. Esta misma opinión fue expresada por un locatario del mercado de Medellín y el dueño de un restaurante Colombiano. Estos actores coincidieron en que la bonanza del mercado para la comercialización de este tipo de alimentos en la década pasada, estuvo relacionada con la amplia presencia de narcotraficantes colombianos en el Distrito Federal y sus alrededores. En ese entonces era común que hombres llegaran al mercado de Medellín y desembolsaran cantidades significativas de dinero en la adquisición de productos. En ocasiones hacían pedidos de dos o tres despensas distribuidas en cajas que contenían los mismos alimentos. Algunas personas consideran que estas compras masivas eran regalos de los narcotraficantes para mujeres y familias con las que se relacionaban. También era común que en ocasiones grupos de hombres llegaran a comprar grandes cantidades de aguardiente antioqueño, lo cual era considerado signo de que un cargamento de drogas se había logrado introducir a México o los EUA. Aunado a esto, la decena de restaurantes colombianos que fueron establecidos en la década pasada eran visitados por consumidores que demandaban grandes cantidades de comida y bebida sin escatimar en gastos.

Hay quienes consideran que inclusive algunos restaurantes servían para lavar dinero del narcotráfico. Lo que si pudo ser confirmado, fue que hacia el año 2011, uno de estos restaurantes era administrado por un artista colombiano que migró a finales de la década de 1990 a los EUA porque fue amenazado por un grupo guerrillero al que criticó en una de sus obras. Después de vivir en diferentes ciudades y ejercer el oficio de panadero, que aprendió de su padre, migró a Canadá donde conoció a su esposa, de origen mexicano. Tras algunos años de trabajar en ese país, la pareja decidió mudarse a la ciudad de México y establecer una panadería colombiana que resultó todo un éxito. En el año 2012 la pareja regresó a Canadá, ya que el esposo fue aceptado como refugiado político. Meses antes de partir, él ya tenía planes de establecer una restaurante colombiano/mexicano en este país. El restaurante colombiano que había establecido en México exponía parte de su obra artística. Otras paredes estaban adornadas con fotos y posters de Colombia. En las mesas se promocionaban distintos destinos turísticos de su país. En la pared principal del establecimiento se exponía un foto-mural de la famosa plaza "El pueblito Paisa" en Medellín. Parte de estos objetos reproducían elementos de 
paisajes con los que se había relacionado de forma íntima a lo largo de sus líneas de vida, pero también se exponían signos con los que jamás había estado en contacto de forma directa, sin embargo, los consideraba representativos de Colombia. Estos objetos y signos representaban paisajes geográficos que había habitado $u$ ocupado (Ingold, 2006,2007 ) y al organizarse en torno a la comida permitían el ensamblaje de un paisaje alimentario colombiano en México :

Foto restaurante colombiano, Ciudad de México

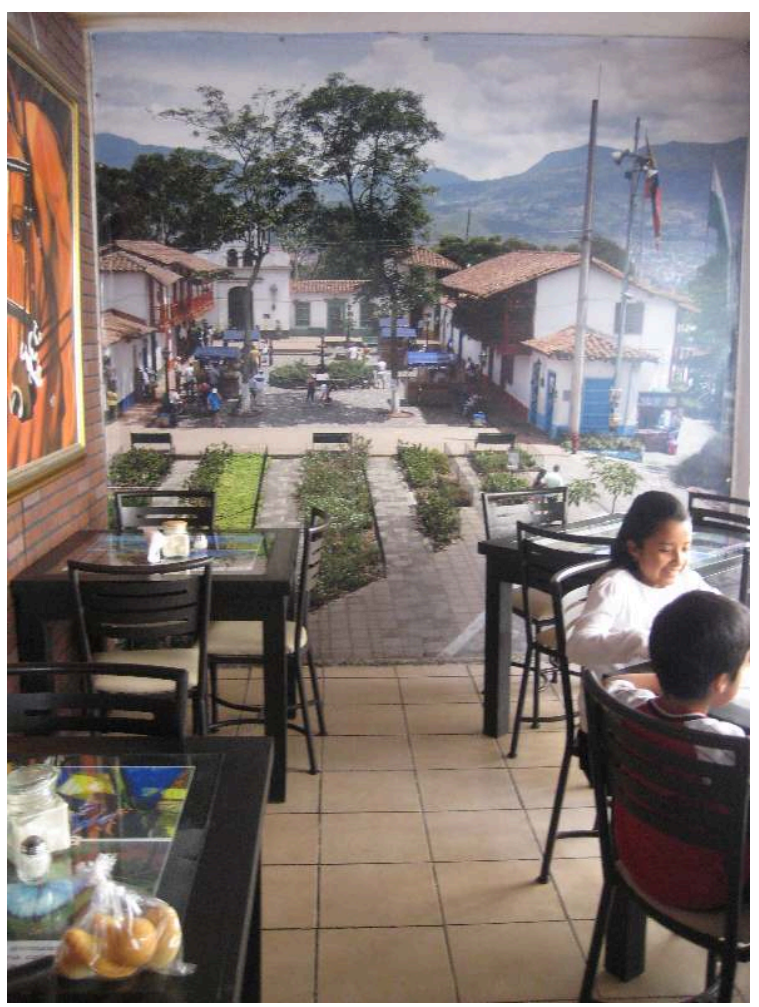

FUENTE : MAXIMINO MATUS, 2011

\section{Alimentos oaxaqueños en Los Ángeles (California)}

Hacia la década de 1980 mujeres zapotecas ${ }^{3}$ originarias de los Valles Centrales y la Sierra norte oaxaqueña ${ }^{4}$ coordinaron a diferentes actores para distribuir y comercializar alimentos entre paisanos migrantes. Algunas ya habían incursionado en el comercio de alimentos en Oaxaca, así como en la venta ambulante de comida preparada en casa - tamales, atole -, o frutas y verduras compradas en la central de abastos de Los Ángeles. Sus clientes eran paisanos de los mismos pueblos y regiones que compartían el gusto por alimentos similares. No obstante, para comercializar alimentos oaxaqueños en Los Ángeles, hacía falta coordinar estas redes con nuevos actores capaces de trasladar desde el terruño originario los bienes que daban razón de ser a sus proyectos empresariales. En algunos casos, el haber accedido a la residencia o ciudadanía estadounidense les permitió realizar viajes entre Oaxaca y Los Ángeles. En caso de no contar con alguno de estos recursos, bastaba con que algún familiar los poseyera y aceptara participar en la empresa. Los aviones les permitieron trasladar con prontitud los alimentos antes de que entraran en proceso de descomposición. 
Diferentes transportes - carros de supermercado, automóviles - les ayudaron a trasladar los alimentos. Las esquinas más transitadas por los paisanos y las casas ubicadas en los distritos de Pico Unión - Oaxacatown -, Santa Mónica y Mar Vista se convirtieron en puntos de venta privilegiados.

La diversificación y el incremento en el volumen de los alimentos comercializados promovieron la reconfiguración del espacio de reproducción del naciente mercado. Es decir, aquellos lugares donde se realizaban encuentros entre actores oferentes y demandantes. En algunos casos las comerciantes pasaron del comercio itinerante a uno de tipo estático mediante la apertura de tiendas y comedores en sus espacios domésticos. Para asistir a estos lugares era necesario conocer a los dueños o ser introducido por otro actor. El hecho de asistir voluntariamente implicaba identificarse como paisano y el reconocimiento del naciente oficio. En estos lugares sólo se vendían productos alimenticios en días y horarios específicos. La viabilidad de la visita se confirmaba de forma previa mediante llamadas telefónicas. De esta manera las comerciantes intentaban protegerse de las autoridades estatales reguladoras de la actividad económica pues, de alguna manera, las comerciantes estaban incurriendo en una actividad ilegal al utilizar sus espacios habitacionales con fines comerciales.

Las precauciones tomadas por las comerciantes no evitaron que, debido a la expansión del mercado, las autoridades estadounidenses intentaran regularlo. Cuando una cantidad considerable de comerciantes zapotecas comenzaron a introducir alimentos oaxaqueños a través del aeropuerto de Los Ángeles y el argumento de que éstos eran para consumo personal dejó de funcionar, las autoridades aduanales prohibieron su entrada. Según argumentaban los inspectores, su comercio violaba las normas vigentes de salubridad alimentaria. En consecuencia las comerciantes comenzaron a introducir los productos en vehículos terrestres por la frontera Tijuana-San Isidro. En esta nueva configuración las comerciantes ya no tenían que viajar necesariamente a Oaxaca, por lo tanto, algunas comenzaron a pedir a sus familiares que les enviaran los alimentos por avión hasta Tijuana. Una vez en Tijuana, las comerciantes introducían los alimentos a los Estados Unidos por la garita de Tijuana-San Isidro, mediante vehículos particulares manejados por ellas mismas o por familiares con residencia o ciudadanía estadounidense.

La nueva práctica se popularizó entre las comerciantes que operaron con redes similares hasta bien entrada la década de 1990. Una de estas cadenas tenía la capacidad de transportar semanalmente hasta dos toneladas de alimentos provenientes del estado oaxaqueño. Esto sentó las bases para que tiempo después aquellos comerciantes que fueron estableciendo formalmente negocios para la venta de comida oaxaqueña, desarrollaran cadenas de distribución capaces de trasportar una mayor cantidad de productos alimenticios frescos antes de que perdieran su calidad en el traslado. Lo anterior fue dando como resultado el desarrollo de cadenas más complejas, surgieron nuevos actores y se introdujeron nuevas tecnologías para su operación. En estas cadenas participan desde familiares y/o amigos que compran y envían los productos de Oaxaca a Tijuana, hasta agentes especializados que "brincan" ${ }^{5}$ de forma clandestina los alimentos por la frontera y personas que "arrastran" los productos a Los Ángeles para surtir a los consumidores y los negocios oaxaqueños. Hasta el año 2006 se habían establecido 45 restaurantes oaxaqueños en el área de Greater Los Angeles (Matus, 2009).

Uno de los primeros restaurantes en abrir fue "Las siete regiones". Este lugar fue establecido por Nadia, migrante originaria del estado de Chihuahua ${ }^{6}$ quien estaba 
casada con un oaxaqueño originario de los Valles centrales. Este caso resulta paradigmático para reflexionar sobre la "autenticidad" de los paisajes alimentarios. El menú que Nadia ofrece en su restaurante, fue constituido después de un largo proceso de dialogo e interpretación entre agentes que además de estar separados por miles de kilómetros, pertenecían a diferentes grupos étnicos ${ }^{7}$, es decir a los zapotecos de los Valles centrales y de la Sierra. Esto fue posible gracias a que su suegra, una zapoteca radicada en los Valles centrales de Oaxaca, le heredó los secretos de su cocina a través de largas conversaciones telefónicas. Al mismo tiempo, su cuñada fue catando y escogiendo cuidadosamente los productos que le enviaba a Los Ángeles hasta que éstos fueron aceptados por sus consumidores, predominantemente zapotecos de la Sierra, como auténticos y de calidad. Lidia fungió como traductora entre zapotecos originarios de los Valles y zapotecos originarios de la Sierra, quienes sin conocerse establecieron un acuerdo sobre el sabor adecuado de los alimentos oaxaqueños y la forma correcta de su elaboración y presentación. Contrario a la opinión de Girard (1996), quien consideraba que las cocinas regionales francesas perdían su coherencia interna al ser comercializadas en las grandes urbes, el caso antes presentado sugiere que el traslado y la traducción de los paisajes alimentarios no implica necesariamente que la gramática alimentaria asociada a una región particular pierda coherencia para sus consumidores.

En seguida se explora una cadena de distribución de alimentos oaxaqueños en Los Ángeles, que originalmente fue constituida por el dueño de uno de estos restaurantes.

A finales de 1997 un migrante oaxaqueño conocido popularmente como "El grillo", estableció su primer negocio para la venta de música, artesanías y comida oaxaqueña en la ciudad de Los Ángeles. Para desarrollar su empresa, El grillo contrató a un paisano con la finalidad de que le ayudara a cruzar por la frontera de San Isidro los alimentos que su hermana le enviaba de Oaxaca a Tijuana. Con el tiempo su trabajador llegó a ser conocido como "El cheese dealer". En una de las ocasiones en que estas dos personas estaban recogiendo sus productos en el aeropuerto de Tijuana, se les acercó el estibador de bodega de una compañía aérea mexicana, a quien aquí identificaremos como "El águila”, y les dijo que también era originario de Oaxaca. Finalmente les pidió trabajo argumentando que conocía el funcionamiento del aeropuerto y podía ser de utilidad para su empresa. A partir de este encuentro fortuito, El grillo se dedicó a atender exclusivamente su negocio en Los Ángeles y El cheese dealer se quedó como encargado de ir semanalmente a Tijuana para recoger y cruzar los productos alimenticios junto con El águila, quien hacia ese entonces radicaba en Tijuana.

31 Con el tiempo, El cheese dealer y El águila comenzaron a surtir de alimentos a otros restaurantes oaxaqueños en Los Ángeles sin que El grillo lo supiera. Cuando se percataban de que alguien estaba recogiendo productos alimenticios que llegaban de vuelos provenientes de Oaxaca, le ofrecían sus servicios. Conforme iban ampliando su cartera de clientes fueron integrando a más trabajadores de origen preferentemente oaxaqueño y con visado, residencia o ciudadanía estadounidense a su cadena paralela de distribución. Después de un par de años decidieron independizarse de El grillo e iniciar un negocio propio orientado específicamente al traslado de productos alimenticios de Tijuana a Los Ángeles. Sin embargo, esta cadena pronto se dislocaría ya que El cheese dealer y El águila, fueron estructurando de manera discreta nuevas cadenas paralelas de distribución y lo mismo sucedería en el futuro con algunos de sus empleados. 
32 En la cadena de distribución inicial construida por El grillo, participaban : 1) su padre, quien enviaba alimentos en taxis desde su pueblo originario en la Sierra Juárez a la ciudad de Oaxaca; 2) su hermana, quien recibía los productos en Oaxaca y sumados a otros alimentos que compraba en la central de abastos, los enviaba por avión a Tijuana; 3) El águila y El cheese dealer, quienes recogían los productos en el aeropuerto de Tijuana y después de varios cruces en camioneta por la frontera, los re-empaquetaban en una bodega de San Isidro para que, finalmente, El cheese dealer los llevara a la ciudad de Los Ángeles. Cuando la cantidad de alimentos trasportados aumentó exponencialmente, El grillo se vio en la necesidad de alquilar también una bodega en la central de abastos de la ciudad de Oaxaca. Según información proporcionada por El cheese dealer, en el año 2001 transportaba semanalmente un promedio de dos toneladas y media de productos para El grillo.

33 El cheese dealer se retiró de este negocio para el año 2003, ya que según argumentó, después del 11 de septiembre del 2001, la seguridad fronteriza aumento considerablemente y por lo tanto cada vez fue más difícil introducir irregularmente productos alimenticios a los Estados Unidos. Durante el tiempo en que se dedicó a esta actividad lo detuvieron en diferentes ocasiones para inspeccionarlo en los cruces fronterizo de Tijuana-San Isidro y la Mesa de Otey, así como en el punto de revisión californiano de San Clemente. Cuando lo detenían argumentaba que los alimentos eran para una fiesta familiar e intentaba respaldarse con su ciudadanía estadounidense y las tarjetas de presentación de diferentes funcionarios del Estado mexicano en ambos lados de la frontera. Si sus argumentos no funcionaban le decomisaban parte o la totalidad de los productos. Los inspectores le advertían que de seguir introduciendo alimentos con la finalidad de comercializarlos, le quitarían la camioneta que utilizaba y su ciudadanía estadounidense. Por lo tanto tenía la necesidad de cambiar de camioneta y cruce fronterizo con regularidad. Otro de los problemas comunes que El cheese dealer enfrentaba estaba relacionado con las autoridades aeroportuarias de Tijuana y de personas que se presentaban como funcionarios de la SAGARPA ${ }^{8}$, quienes al percatarse del auge de esta actividad, comenzaron a demandar pagos monetarios para no confiscar los alimentos. Esto mismo les sucedió a diferentes comerciantes que solían ir a recoger los alimentos que sus familiares les enviaban al aeropuerto de Tijuana. Por lo tanto, la demanda de servicios especializados como los ofrecidos por El cheese dealer y El águila aumentó con facilidad, incentivando la multiplicación de actores especializados en el área de las cadenas de distribución. El cheese dealer comentó que para el año 2003, calcula que se introducían alrededor de 40 toneladas de productos oaxaqueños semanalmente a los Estados Unidos.

34 Cuando El cheese dealer salió del negocio, la cadena de distribución conformada por El águila se consolidó como la más importante para abastecimiento de alimentos oaxaqueños en Los Ángeles. Hasta el año 2009, al interior de esta cadena de distribución, un grupo se encargaba de recoger los productos al aeropuerto de Tijuana. Después éstos eran llevados a una de las casas de El águila en la ciudad, donde se reempaquetaban preferentemente en bolsas de comercios locales con diferentes colores para distinguir a cada uno de los destinatarios. Una vez reempaquetados, pequeños grupos de dos o tres personas cruzaban los alimentos hacia EUA a pie y en coche o camionetas a través de la frontera Tijuana-San Isidro. En otros casos, si la vigilancia era estricta, utilizaban el cruce de La Mesa de Otey. 

guardados en una bodega de San Isidro, en donde había otro grupo que esperaba a que se juntara una cantidad considerable para llevarlos en camionetas a Los Ángeles y comenzar la distribución de los mismos. En caso de que éstos hubieran sido enviados en el primer vuelo del día de Oaxaca-Tijuana, era posible que los comerciantes recibieran sus productos el mismo día por la noche, si eran recogidos en la casa donde estaban almacenados, o al siguiente día por la mañana directamente en sus establecimientos.

A principios del año 2006, la red conformada por El águila, contaba con más de 20 empleados. La mayoría poseía visa, residencia o ciudadanía estadounidense. En las distintas temporadas de trabajo de campo que realice durante los años 2005 y 2006 en la ciudad de Los Ángeles, los comerciantes eran reacios a admitir que en ocasiones ellos mismos introducían ilegalmente los alimentos por la frontera. Asimismo, les costaba trabajo aceptar que contrataban los servicios de terceros para realizar dicha actividad. Por lo general ocultaban los nombres de estas personas porque no querían tener problemas con ellos y correr el riego de perder un eslabón importante para la operación de la cadena agroalimentaria. Paradójicamente, hacia finales del año 2006, El águila, ya anunciaba públicamente sus servicios en un periódico de la ciudad de Los Ángeles. En su publicidad aparece un ave expresando su beneplácito alzando una de sus plumas/dedos del ala/mano derecha. Esta ave se encuentra posicionada en medio de la bandera mexicana y la estadounidense. Con este símbolo, El águila representa la constitución de un espacio fluido entre ambos países; el paisaje alimentario de Oaxaca puede ser reensamblado en Los Ángeles sin importar las diferencia de leyes que regulan la inocuidad alimentaria :

Foto tomada del Periódico Impulso Oaxaqueño, Los Ángeles, marzo, 2006

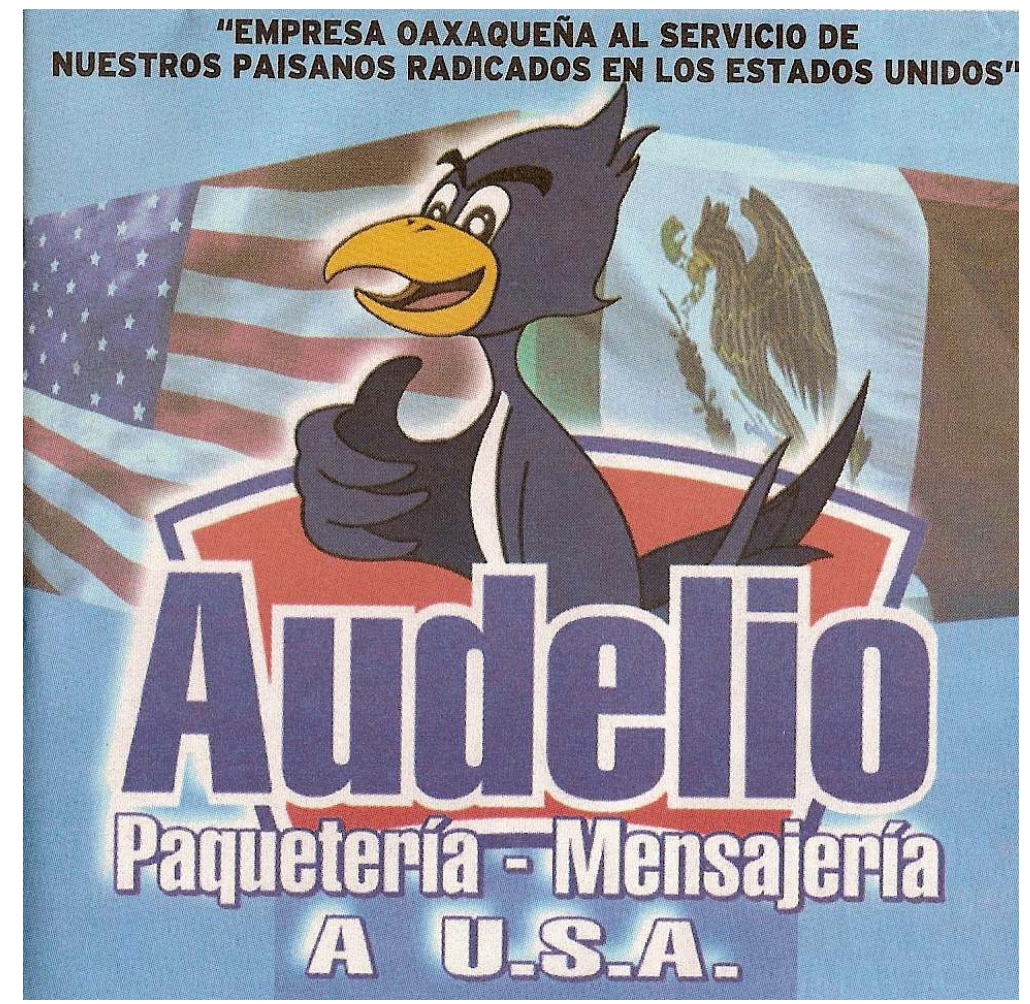

FUENTE : MAX MATUS 


\section{El panorama alimentario de una comunidad transnacional}

Desde la década de 1990 más de una docena de restaurantes que se promocionaban como mayas o yucatecos se habían establecido formal e informalmente en el área de la Bahía de San Francisco. La mayoría de sus dueños eran migrantes originarios del municipio de Oxkutzcab, Yucatán. Aunque también se identificaron a migrantes de otros estados de la República Mexicana, así como de países europeos y asiáticos que habían formado sociedades para establecer restaurantes mayas/yucatecos. En algunos casos, las salas de las casas fueron acondicionadas como negocios para la venta de comida entre paisanos, mientras que en otros, se optó por el establecimiento formal de restaurantes con la intención de captar a un público más amplio. Los primeros restaurantes solían ser identificados con el nombre de sus dueños - Tommy's, La casa de Doña Clote, Donde Delmy-, mientras que los más recientes fueron retomando palabras que hacen referencia directa a la cultura maya y la identidad yucateca - entre ellos, Poc Chuc, Chaac Mool, y Mi Lindo Yucatán (Matus, 2012). En el año 2008, el proceso de expansión del mercado para la venta de alimentos yucatecos en San Francisco llegó al punto de crear una palabra que implosiona geografías globales de hemisferios opuestos : Yucatasia. Este restaurante fue abierto por un migrante vietnamita que se comunicaba en maya con sus trabajadores, quienes en su mayoría eran originarios del municipio de Oxkutzcab.

Al igual que los migrantes zapotecos para el caso de Los Ángeles, algunos migrantes mayas originarios del estado de Yucatán, se han dedicado a la comercialización de alimentos en la ciudad de San Francisco (California). Por lo común transportan alimentos debidamente enlatados y empaquetados : galletas Donde, embutido de cerdo Tulip, queso Gouda El Gallo y condimentos conocidos localmente como "recados", son los más comunes. El comercio de estos alimentos se realiza mediante el ambulantaje, en casas particulares y restaurantes. En el año 2009 existían cerca de 50 personas que se dedicaban a trasladar alimentos y productos entre las diferentes agencias del municipio de Oxkutzcab, la Bahía de San Francisco y Portland (Oregón). Los comerciantes ofrecen sus servicios a través de cartulinas que pegan frente a sus casas, donde anuncian que se aceptan "encargos", su fecha de salida y el destino. Algunos comerciantes también hacen recorridos por las diferentes agencias del municipio para recoger los productos. Una vez que estos son recabados, los comerciantes inspeccionan con cuidado cada uno de los "encargos" para estar seguros de lo que llevan, ya que en ocasiones han tenido severos problemas con las autoridades sanitarias estadounidenses por transportar alimentos prohibidos.

Los comerciantes comentaron que las inspecciones aduanales en el aeropuerto de San Francisco se tornaron más estrictas después de los atentados del 2001 y fueron reforzadas a partir del año 2007. Desde entonces fue necesario que toda persona dedicada al traslado de alimentos se diera de alta ante las autoridades estadounidenses y llenara un formulario donde especificara con exactitud la cantidad y el tipo de productos transportados antes de tomar un avión con dirección a esa ciudad, de lo contrario serían acreedores a una pena severa. Cuando los comerciantes inspeccionan los productos para llenar los formularios aduanales, se han encontrado con ingeniosas técnicas para enviar frutos u otro tipo de alimentos prohibido sólo a los migrantes. Por 
ejemplo, en una ocasión un queso Gouda ${ }^{9}$ - alimento altamente apreciado en la región porque es utilizado para elaborar una comida tradicional llamada "queso relleno" -, fue confiscado en la aduana y su portadora recibió una multa porque al pasar por los rayos $\mathrm{X}$ se identificó que en su interior llevaba una ciruela. La comerciante que lo transportaba argumentó que alguien más se lo había dado y que no se había percatado de que el queso estaba "relleno". Cuando regresó de San Francisco reclamó a la persona que lo había enviado y esta se disculpó argumentando que lo hizo porque su hijo le había comentado que extrañaba mucho el sabor de las ciruelas de su pueblo.

La anécdota antes presentada llama la atención por dos cosas. En primer lugar, es curioso que una ciruela haya causado la alarma de las autoridades sanitarias estadounidenses, pero no el queso que la transportaba en su interior. La diferencia radicó en el hecho de que este último producto se encontraba debidamente regulado, mientras que la ciruela no. En segundo lugar puede parecer extraño que un migrantes maya haya pedido a su madre que le enviara una ciruela. Pero es importante recordar que los paisajes alimentarios también se forman trazando las líneas fluidas de vida. Seguramente este alimento guardaba un significado más profundo para el migrante.

\section{Restaurantes internacionales en Oxcutzcab, Yucatán}

Algunos investigadores han estudiado los restaurantes establecidos por los migrantes en las sociedades receptoras como espacios para recrear las identidades étnicas y reforzar las nociones de comunidad (Bell y Valentine, 1997). Empero, este no siempre es el caso. Si bien, en estos lugares los paisajes alimentarios adquieren una base material para ser aceptada o impugnada, son los migrantes quienes deciden si aceptan o no dichas representaciones. Ahora bien, ¿qué pasa cuando los migrantes establecen restaurantes internacionales en sus comunidades de origen?

Los comerciantes de Oxcutzcab no solo trasladaban alimentos de Yucatán a EUA, sino que a su regreso también introducían productos a México; tecnologías y ropa son los más comunes, pero en ocasiones también transportaban alimentos italianos o asiáticos encargados por ex migrantes que tras años de vivir en los EUA regresaron a sus comunidades de origen y decidieron abrir un restaurante. La práctica de abrir restaurantes internacionales en este municipio maya era relativamente común hasta el año 2012. Esto se debía a que la mayoría de los hombres que migran a San Francisco se habían empleado en restaurantes. Por lo común iniciaban como ayudantes de mesero y después de años de trabajo algunos llegaban a ser chef o gerentes. De hecho, la mayoría de los restaurantes mayas/yucatecos en San Francisco fueron establecidos por personas que trabajaron durante mucho tiempo en restaurantes y alcanzaron puestos altos. Por su parte, algunos migrantes que también ocuparon buenos puestos laborales en restaurantes de los EUA, decidieron regresar a Oxcutzcab y probar suerte estableciendo negocios para la venta de comida asiática, italiana, francesa, salvadoreña o "estadounidense".

Hasta el año 2012 se habían establecido -algunos ya han cerrado- siete restaurantes para la venta de comida asiática, -predominantemente china-, dos "estadounidenses", un italiano y un establecimiento que además de comidas locales, ofrecía popusas salvadoreñas. También se tuvo conocimiento de un restaurante que ofertaba comida asiática, italiana y francesa, ya que su dueño había trabajado en diversos restaurantes internacionales en los EUA. Sin embargo, este lugar cerró sus puertas en el año 2008. 
Además, un ex migrante también se dedicaba a vender comida china en tres estantes móviles que por la noche estacionaba en las plazas de las agencias municipales. Para atraer la atención de los consumidores, el empresario adornó estos puestos con techos de dos aguas y los pintó de rojo, simulando un patrón estético que recordaba a cierta arquitectura oriental. La mayoría de los restaurantes se encontraban establecidos en casas. Estos espacios habían sido acondicionados en coordinación con el paisaje geográfico de la comida que comercializaban; cuadros, posters, objetos, colores distintivos y música ayudaban reensamblar paisajes alimentarios internacionales. Por ejemplo, el dueño de un restaurante que comercializaba hamburguesas estilo San Francisco había modificado la fachada de su casa para crear semejanza con el paisaje de la ciudad estadounidense :

Fachada de casa/restaurante, Oxcutzcab, Yucatán

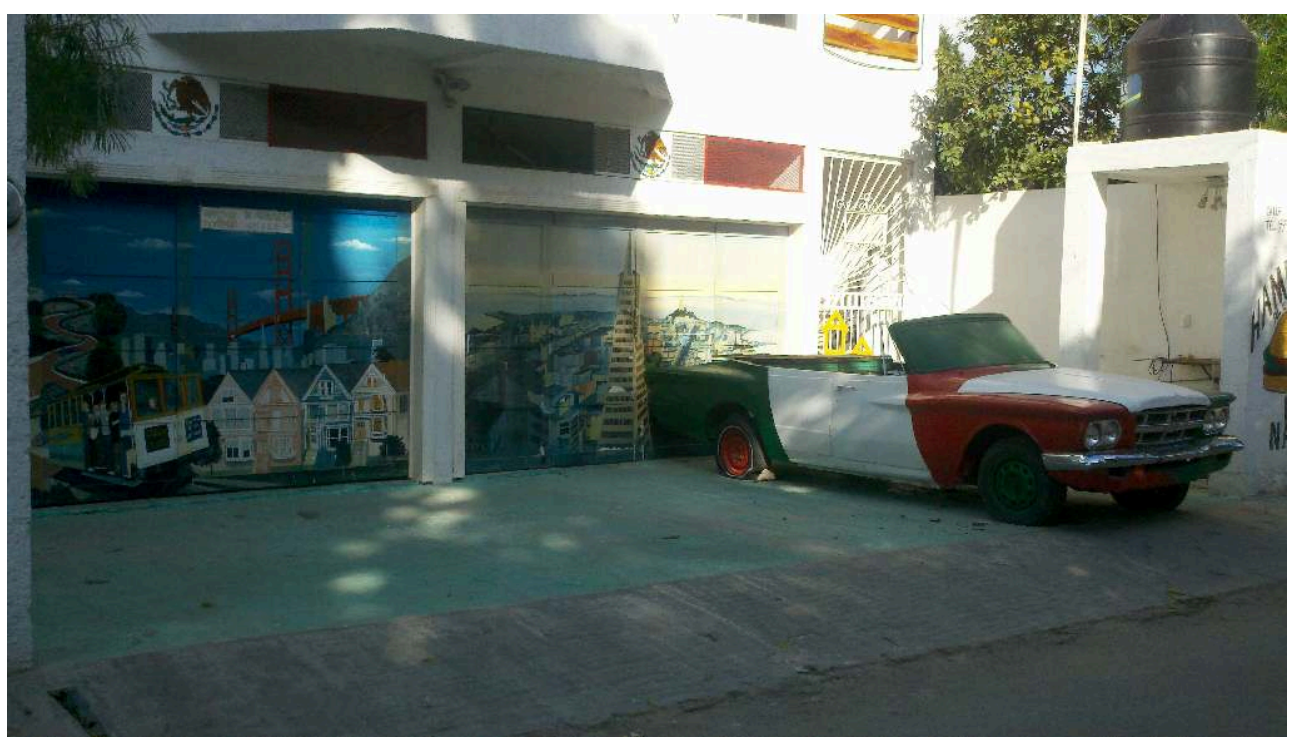

Fuente: Maximo Matus, 2012.

Aunque la mayoría de los condimentos y productos necesarios para preparar estas gastronomías pueden adquirirse en México, algunos dueños de estos restaurantes preferían seguir comprando sus productos con los comerciantes transnacionales ya que según aseguraban, la calidad de los productos que se venden en los EUA es mejor. También habían algunos empresarios que realizaban viajes a Belice para comprar sus productos en la tiendas chinas establecidas en la zona libre de esta ciudad fronteriza. Generalmente, estos empresarios viajaban en sus coches los fines de semana por las mañanas y regresaban a México a altas horas de la noche para evitar ser inspeccionados por los puntos fronterizos localizados a unos kilómetros dentro del lado mexicano. En caso de que los detuvieran era común que las autoridades mexicanas les solicitaran el pago de una "multa apócrifa", independientemente de que hubieran excedido o no la franquicia establecida.

En la última visita a la comunidad, hacia el año 2012, se constató que el auge por las cocinas internacionales en Oxcutzcab llevó a que al interior del mercado central de la comunidad se estableciera un restaurante chino y otro italiano. Desde las 7am el restaurante chino era frecuentado por decenas de consumidores que compraban paquetes que incluían tres o cuatro guisos a escoger de una barra. Algunos pedían los 
alimentos para llevar, pero la mayoría los consumían al interior del mercado. Por los común a medio día los alimentos preparados se habían terminado. Aquellos consumidores que se quedaban con antojo podían adquirir estos mismos productos a partir de las $5 \mathrm{pm}$ en la casa particular de este empresario, donde también había establecido un restaurante. Debido a que el negocio se encontraba sobre una carretera que atraviesa la comunidad, no era raro que algunos residentes de las agencias aledañas compraran su cena en este lugar antes de regresar a sus hogares.

Al igual que los evangelistas brasileños que visitaban el mercado de Medellín después de misa, los católicos mayas gustaban de consumir comida china los días domingo después de misa de las $12 \mathrm{pm}$ y las $6 \mathrm{pm}$. Esta fecha y horarios prácticamente aseguraban un lleno total para los establecimientos que vendían comida china. Este hecho sugiere que esta gastronomía ha sido incluida al paisaje alimentario de la comunidad a partir de su conexión con el ciclo ritual de la misma. La comida china ha logrado introducirse en otros eventos rituales como los bautizos, los XV años y las bodas. Los alimentos orientales han reemplazado en ocasiones a los yucatecos. Para algunos resulta incluso más atractivo convivir con chopsuey que hacerlo con panuchos.

Otra de las formas como los migrantes habían impulsado la resignificación del paisaje alimentario de esta comunidad maya fue a través de llamadas telefónicas o conversaciones por computadoras, en las que sugerían a sus familiares que visitaran estos restaurantes y consumieran este tipo de alimentos para que degustaran lo que ellos cocinaban en los restaurantes de San Francisco. Algunos empresarios aseguraba que mujeres de edad avanzada, provenientes de otras comunidades, habían llegado a sus establecimientos para probar estos alimentos. Ya entrados en plática les comentaban que habían visitado el lugar porque sus hijos o esposos en los EUA se los habían solicitado. Gracias a estas prácticas, los paisajes alimentarios de San Francisco y Oxcutzcab eran ensamblados en el paladar y la mente de consumidores que se encontraban separados por miles de kilómetros, pero que se unían momentáneamente por su afección expresada a través de la comida.

El entrelazamiento de las políticas nacionales de control alimentario, las afecciones personales por comida venida allende la frontera, y los cambios alimentarios expresados en los rituales comunitarios que han sido explorados en el cuerpo de este articulo, traen a colación la tesis Deleuzeana retomada por Dolphijn (2004) en su análisis sobre los paisajes alimentarios de Hangzhou, Boston, Bangalore y Lyon: "la comida funciona en estructuras inmanentes que están siempre en proceso de cambio" (Dolphijn, 2004 : 8. Traducción propia). Los alimentos que hoy están asociados a espacios determinado, mañana perderán su referente territorial.

\section{Conclusiones}

En este artículo se exploraron diferentes estrategias utilizadas por comerciantes para trasladar alimentos entre EUA y diversos países latinoamericanos. Mientras algunos actores realizan su actividad de manera solitaria, pero con ayuda de diversas tecnologías, otros han logrado conformar grandes colectivos empresariales que operan diversos eslabones de cadenas agroalimentarias. Estos conglomerados de actores, objetos y tecnologías, ligan diferentes geografías con la finalidad especifica de trasladar alimentos que no cumplen con los estándares de calidad de los territorios donde los comercializan, o en caso de sí hacerlo, sus precios son elevados y su sabor difiere del 
"original". En su actuar, los colectivos empresariales ponen en cuestión las regulaciones de los Estados-Nación que evalúan la inocuidad de los alimentos que entran a sus territorios, así como los precios fijados por las empresas que sí cumplen con dichas normativas y la forma específica de producirlos. Éstos son ejemplos claros de prácticas políticas y económicas emprendidas por actores que luchan por la inclusión de sus panoramas alimentarios en geografías distintas a las que comúnmente están relacionados.

Otra razón común que impulsa el traslado clandestino de este tipo de alimentos, esta relacionada con el afán de los migrantes por reensamblar las líneas fluidas de sus vidas que fueron fragmentadas simbólica y físicamente al cruce con las fronteras nacionales. La nostalgia de un migrante por el sabor, olor y textura de un alimento, no implica que ésta sea exclusiva a las características específicas del producto físico, sino que se extiende a los múltiples organismos y objetos que en su conjunto conforman el paisaje alimentario del migrante. La afectividad asociada a la ciruela del árbol del llano en que alguien solía jugar cuando era niño, pueden ser un detonante capaz de promover el traslado de alimentos entre diferentes países con la finalidad de reensamblar un paisaje alimentario fuera del territorio donde originalmente fue experimentado. Por lo tanto, es posible argumentar que las múltiples pasiones que los migrantes tienen por los paisajes alimentarios que han experimentado en su vida, promueven el quebrantamiento de las fronteras nacionales.

51 Si bien, algunos migrantes logran contaminar su pasión por ciertos alimentos entre los miembros de sus comunidades de origen o destino, el recuerdo afectivo, asociado a un paisaje alimentario no puede ser contaminado. En su lugar, cada actor va creando relaciones afectivas particulares con los alimentos; algunas son sumamente íntimas, otras son compartidas entre múltiples actores, empero, en su conjunto tienen la capacidad de traducir paisajes alimentarios. La incorporación de comida asiática a los rituales sociales de una comunidad maya ejemplifica la traducción de un paisajes alimentario, consecuencia del encuentro de afecciones intimas y colectivas.

En otra veta de análisis, los datos empíricos presentados en este articulo demostraron que la infraestructura utilizada para trasladar alimentos de un país a otro, por los colectivos empresariales analizados, es carente. La mayoría de los empaques, transportes y almacenes a los que recurren son inadecuados para la preservación optima de los alimentos. No obstante, estas restricciones son superadas por la rapidez con la que realizan su actividad y la eficacia que tienen para vender sus productos antes de que pierdan algunos de sus atributos distintivos o entren en proceso de descomposición. El bajo perfil tecnológico de la infraestructura necesaria para incursionar en esta actividad ha permitido que múltiples actores participen en el mercado del traslado clandestino de alimentos o salgan con facilidad del mismo, debido a que esto no implica la perdida de alguna inversión material. En consecuencia, si el bajo perfil tecnológico impulsa la dinámica de estos mercados, toda política persecutoria que intente regular su funcionamiento fracasará; siempre habrá algún actor dispuesto a correr el riesgo.

53 Una estrategia alternativa a las políticas persecutorias que pretenden excluir de los territorios nacionales a aquellos alimentos que no se adecuan a sus leyes de calidad e inocuidad, sería la de crear leyes de excepción que permitan comerciar en pequeña escala con este tipo de productos, siempre y cuando sean destinados primordialmente a comunidades migrantes y otros actores dispuestos a correr el "riesgo" de consumirlos. 
Para dicho efecto se podrían crear etiquetas especiales para identificarlos con leyendas como : "la calidad de este producto no cumple con los estándares de inocuidad vigentes en este país". Si de cualquier forma los consumidores aceptan introducirlos a su cuerpo, las autoridades estatales no tendrían porque alarmarse; los migrantes estarían ejerciendo su derecho a mantener sus prácticas alimentarias fuera del país de origen y los "consumidores arriesgados" estarían ejerciendo su derecho a relacionarse plenamente con paisajes alimentarios foráneos. De forma contraria, las fronteras nacionales de América seguirán siendo fragmentadas por las líneas de vida tendidas por los migrantes latinoamericanos para reensamblar sus paisajes alimentarios.

\section{BIBLIOGRAPHIE}

ADEMA Pauline, Festive Foodscapes : Iconizing Food and the Shaping of Identity and Place, Austin, University of Texas, PhD dissertation, 2006.

BELL David and VALENTINE Gill, Consuming Geographies: We Are Where we Eat, USA, Routledge, 1997.

COSGROVE Denis, « icas año consideran distintivo de sus tradiciones culinarias.Modernity, Community and the Landscape Idea ", Journal of Material Culture, vol. 11, n 1-2, 2006, pp. 49-66.

DANIELS Stephen, Fields of Vision : Landscape Imagery and National Identity in England and the United States, Oxford Polity Press, 1993.

INGOLD Tim, The Perception of the Environment. Essays in Livelihood, Dwelling and Shill, London and New York, Roudledge, 2006.

INGOLD Tim, Lines : A Brief History, London, Roudledge, 2007.

LATOUR Bruno and LÉPINAY Vincent, The Science of Passionate Interest : An Introduction to Gabriel Tarde's Economic Anthropology, Chicago, Prickly Paradigm Press, 2009

MATUS Maximino, Affective Foodscapes in an Economy of Passion : Repetition, Opposition and Adaptation in Mexican Restaurants in Amsterdam, Madrid and San Francisco, Wageningen University (Netherlands), PhD dissertation, 2012.

MATUS Maximino, «Construyendo y debatiendo la calidad del quesillo artesanal oaxaqueño en Los Ángeles (California) » in Guadalupe RODRÍGUEZ GÓMEZ y K. Appendini (coords.), La paradoja de la calidad. Alimentos mexicanos en América del norte.México, COLMEX, 2011, pp. 229-254.

MATUS Maximino, « El ingrediente étnico : Alimentos y restaurantes Oaxaqueños en Los Ángeles ", RURIS I, vol. 3, 2009, pp. 41-69.

MITCHELL Don, The Lie of the Land: Migrant Workers and the California Landscape, Minneapolis University of Minnesota Press, 1996.

MITCHELL William J.T., Landscape and Power, University of Chicago Press, 2002.

JOHNSTON Josée, BIRO Andrew and MACKENDRICK Norah, « Lost in the Supermarket: The Corporate-Organic Foodscape and the Struggle for Food Democracy », Antipode, vol. 41, n 3, 2009, pp. 509-532. 
YASMEEN Gisèle, « Plastic Bag Housewives and Postmodern Restaurants : Public and Private in Bangkok's Foodscape » in Carole COUNIHAN and Penny Van ESTERIK (eds.), Food and Culture : A Reader, London, Routledge, $2^{\text {nd }}$ edition, 2008.

YASMEEN Gisèle, Bangkok's Foodsape : Public Eating, Gender Relations and Urban Change, Vancouver, University of Brithish Columbia, 1996.

UEXKÜLL (von) Jakob, « A Stroll Through the World of Animals and Men : A Picture Book of Invisible Worlds », Semiotica, vol. 89, n 4, 1992 [1934], pp. 319-391.

\section{NOTES}

1. Los datos etnográficos aquí presentados fueron obtenidos mediante entrevistas abiertas y semi-estructuradas, así como observación participante e interacciones informales sostenidas con dueños, trabajadores, distribuidores y consumidores de comercios y restaurantes en Los Ángeles (California), San Francisco, la Ciudad de México, la ciudad de Oaxaca y la comunidad de Oxcutzcab, Yucatán, México, entre los años 2005 y 2012.

2. La palabra "Paisa" es utilizada popularmente para designar a los oriundos de la región de Antioquia (Colombia).

3. Los Zapotecos son un grupo étnico del Estado de Oaxaca.

4. Oaxaca es un Estado de la República Mexicana ubicado al sur del país caracterizado por una alta marginalidad y una fuerte tasa de expulsión migratoria. Su población está conformada por 16 grupos étnicos. Está dividido políticamente en 570 municipios y 7 regiones (Valles Centrales, Istmo, Papaloapan, la Cañada, Sierra Norte, Sierra Sur, la Mixteca y la Costa).

5. Brincan y arrastran son términos comúnmente utilizados por los actores entrevistados y hacen referencia al transporte de alimentos a través la frontera.

6. Estado de la República Mexicana ubicado en el norte de México.

7. En Oaxaca se distinguen tres grupos de zapotecos en relación al espacio geográfico donde habitan : sierra, valles e istmo. Cada uno de estos grupos habla una variantes del idioma que los identifica como parte del mismo grupo étnico.

8. Secretaría de Agricultura, Ganadería, Desarrollo Rural, Pesca y Alimentación (SAGARPA).

9. Popularmente se le conoce como "queso de bola" debido a la forma que lo caracteriza.

\section{RÉSUMÉS}

Le but de cet article est d'explorer les stratégies employées par les marchants et différents acteurs de la distribution, ainsi que les technologies qu'ils utilisent, pour introduire clandestinement des aliments de divers pays d'Amérique Latine aux États-Unis. Ces produits sont destinés aux consommateurs qui ressentent une certaine nostalgie des formes, des saveurs et des textures alimentaires liées aux espaces nationaux où ils ont habités. Les produits qui évoquent des représentations de paysages leur rappelant leurs origines sont également destinés à d'autres commerces ou boutiques. La thèse principale de cet article avance l'idée selon laquelle, ceux qui participent à ce marché participent également à la promotion de la fragmentation des frontières nationales. De ce fait, ils font un assemblage de paysages alimentaires en dehors des territoires 
avec lesquels ils interagissent habituellement. Bien que certains acteurs aient vécu une expérience directe en lien avec ces paysages alimentaires, l'expérience d'autres acteurs ne se limite pas à cette représentation de ces paysages. Dans la pratique, l'assemblage de ces représentations et de ces expériences a encouragé l'émergence d'une économie dont la reproduction est basée sur la diffusion de la passion pour les aliments exotiques.

This article explores the strategies deployed by different groups of distributors and merchants, as well as the techniques they used to introduce food illegally from Latin American countries to the United States. The final consumers of these products are nostalgic migrants eager of the forms, flavors and textures of the places they come from. Other clients of these goods are stores and business whose products remind immigrant the landscapes and representations of their origins. Our main argument is that those who are involved in this market also promote the fragmentation of national boundaries. Their most important ambition is to join different food landscapes, despite being outside the territories with which they usually interact. Although, a part of these consumers have had a direct experience of these food landscapes, others actors are not limited to these representations. In practice, the combination of these representations and experiences encourage the emergence of a particular economy. The reproduction of this economy is based on the diffusion of consumers' passion for exotic food.

El presente artículo tiene por objetivo explorar algunas estrategias empleadas por colectivos de distribuidores, comerciantes y tecnologías asociadas, para trasladar e introducir alimentos de forma clandestina entre EUA y diversos países latinoamericanos. Estos productos son destinados a consumidores que añoran formas, sabores y texturas alimentarias relacionadas con los espacios que han habitado, así como por establecimientos que suelen comercializarlos en complicidad de representaciones paisajísticas que evocan su origen. Se argumenta que los diversos actores que participan en estos mercados promueven la fragmentación de las fronteras nacionales, con la finalidad de ensamblar paisajes alimentarios fuera de los territorios con los que comúnmente se relacionan. Mientras algunos actores han experimentado estos paisajes alimentarios de forma directa, otros sólo se han relacionado con sus representaciones; en la práctica, el ensamblaje de la representación y experimentación ha promovido la emergencia de una economía que basa su reproducción en la contaminación de la pasión por alimentos provenientes allende las fronteras.

O presente artigo tem como objectivo explorar algumas estratégias usadas pelos colectivos de distribuidores, comerciantes e tecnologias associadas, para transportar e introduzir alimentos de forma clandestina entre os EUA e diversos países latino-americanos. Estes produtos são destinados aos consumidores que sentem saudades das formas, sabores e texturas dos alimentos relacionadas com os espaços que têm habitado, assim como pelos estabelecimentos que costumam comercializá-los em cumplicidade com as representações paisagísticas que lembram a sua origem. Argumenta-se que os diversos atores que participam nestes mercados promovem a fragmentação das fronteiras nacionais, com a finalidade de montar as paisagens alimentares fora dos territórios com os quais se relacionam frequentemente. Enquanto alguns atores têm experimentado estas paisagens alimentares de forma direta, outros só se têm relacionado com suas representações; na prática, a montagem da representação e experimentação tem promovido o surgimento duma economia que baseia sua reprodução na contaminação da paixão pelos alimentos vindos de além fronteiras. 
INDEX

Mots-clés : affection, économie de la passion, frontières nationales, paysages alimentaires

Palavras-chave : afeição, economia da paixão, fronteiras nacionais, paisagens alimentarias

Palabras claves : afección, economía de la pasión, fronteras nacionales, paisajes alimentarios

Keywords : affection, passion economy, national boundaries, food landscapes

\section{AUTEUR}

\section{DR. MAXIMINO MATUS RUIZ}

Investigador en el Infotec-CONACYT, México. maximinopointmatusatinfotecpointcompointmx, maximinopointmatusatgmailpointcom. 